\title{
The Nature of Middle School Learners' Science Content Understandings with the Use of On-line Resources
}

\author{
Joseph L. Hoffman, Hsin-Kai Wu, Joseph S. Krajcik, Elliot Soloway \\ School of Education, University of Michigan, 610 E. University, Ann Arbor, \\ Michigan 48109-1259
}

Received 22 March 2002; Accepted 4 June 2002

\begin{abstract}
Early research on using the World Wide Web indicated that middle school students did not explore much and used Web tools naively. In response to these challenges, an on-line research engine, Artemis, was designed to provide a permanent workspace and allow students access to preselective on-line resources. This study investigated the depth and accuracy of sixth-grade students' content understandings as well as their use of search and assess strategies when they used on-line resources via Artemis. Eight student pairs from two science classes experienced support from teachers and used scaffolded curriculum materials while completing four on-line inquiry units during 9 months. Multiple sources of data were collected, including video recordings of students' computer activities and conversations, students' artifacts and online postings, classroom and lab video recordings, and interview transcripts. Analyses of data showed that students constructed meaningful understandings through on-line inquiry, although the accuracy and depth of their understandings varied. The findings suggest that students might develop accurate and in-depth understandings if they use search and assess strategies appropriately, if resources are thoughtfully chosen, and if support from the learning environment is extensively provided. This research lends evidence to questions regarding the value of students engaging in on-line inquiry. (c) 2003 Wiley Periodicals, Inc. J Res Sci Teach 40: 323-346, 2003
\end{abstract}

Educators in the 20th century have seen a number of technological innovations enter into science classrooms across the United States. The most recent innovation for classrooms, the use of the World Wide Web (WWW), offers yet another opportunity for enhancing the ways in which teachers teach and learners learn, although this claim has been left largely unexamined. The increased reliance on the World Wide Web for providing educational experiences to Grade $\mathrm{K}-12$ learners requires the immediate attention of the research community. Advocates (Barrie \& Presti, 1996; Kinzie, Larsen, Burch, \& Boker, 1996; Ryder \& Graves, 1997) speak to the potential of the WWW as an instructional tool for classrooms. The Internet and WWW could change the nature

\footnotetext{
Contract grant sponsor: NSF/DARPA/NASA Digital Library Initiative; Contract grant number: IRI-9411287; Contract grant sponsor: NSF NIE; Contract grant number: RED-9554205.

Correspondence to: Hsin-Kai Wu; E-mail: hkwu@umich.edu

DOI 10.1002/tea.10079

Published online in Wiley InterScience (www.interscience.wiley.com).
} 
of learning by increasing access to instructional materials in a variety of media (Kinzie et al., 1996), promoting students' skills in information gathering and problem solving (Ryder \& Graves, 1997), encouraging network collaborations (Tinker \& Haavind, 1997), and having access to decentralized resources (Tinker \& Haavind, 1997).

However, although a large collection of literature speaks to the positive nature of the use of WWW resources in science classrooms, other sources (Lookatch, 1995; Maddux, 1996; Winebrener, 1997; Stoll, 1998) remain pessimistic on its application as an instructional tool. Winebrener (1997) showed that students can become misled by viewing falsified information posted on the Web, frustrated owing to an inability to locate specific information easily, and confused with varying forms of navigation found on individual pages. Maddux (1996) supported these cautions and argued that the assumption that hypermedia and open-ended exploration of data are more consistent with the way children think has not been verified through research yet.

The complexity of these issues and messages provides uncertain guidance to policymakers and educators who continue to implement these tools in classrooms across the United States. Given the variety of literature for both positive aspects and challenges associated with using the WWW in Grade K-12 classrooms, it is critical to provide empirical evidence of its affect on schools.

This study was part of a series of design experiments within an intensive educational project and conducted based on principles delineated by Brown (1992) and Collins (1999). It was initiated in response to prior work on using the WWW (Hoffman, Kupperman, \& Wallace, 1997; Lyons, Hoffman, Krajcik, \& Soloway, 1997; Wallace, Kupperman, Krajcik, \& Soloway, 2000) that showed a mismatch between the intended goals of the project and behaviors of students as they engaged in on-line investigations. Students did not explore much, did not evaluate sources, tended to seek answers rather than aim for understanding, and used Web tools naively. In response to this feedback, an information-seeking interface, Artemis, ${ }^{1}$ was designed based on learner-centered design principles (Soloway, Guzdial, \& Hay, 1994). This interface, including a research engine and a permanent workspace, allows students access to a digital library that contains preselective, preapproved, and age-appropriate on-line resources for middle school learners. It helps students focus on the content of the on-line resource, evaluate its usefulness, and synthesize information rather than spending the majority of time simply locating appropriate sites on the WWW.

In addition, Wallace et al. (2000) concluded that factors influencing student's actions during on-line sessions were the pedagogical approach employed by the teacher and corresponding degree of support received during the inquiry units, both on- and off-line. Therefore, this study developed on-line and off-line learning materials to provide scaffolding, which allowed students to accomplish tasks they could not do alone (Wood, Burner, \& Ross, 1976; Palinscar \& Brown, 1984), to support students' information-seeking activities as they asked question of interest, searched for information, assessed their findings, and created rich representations of their newly constructed understandings.

This yearlong study investigates the depth and accuracy of sixth-grade students' content understandings as well as their use of search and assess strategies as they used on-line resources via Artemis. This study focuses on the following questions:

1. What depth and accuracy of content understanding do learners demonstrate with the use of on-line resources? To what extent are these made visible in learners' products and conversations?

2. What insights can be suggested between learners' use of search and assess strategies and the depth and accuracy of content understandings that they demonstrate?

3. What insights can be suggested regarding the quality of on-line resources and the depth and accuracy of content understandings that they demonstrate? 
This research lends evidence to questions regarding the value of the WWW as a viable medium for learning by providing an empirical perspective on students' emergent content understandings. Also, it follows learners throughout the entire school year, whereas previous studies did not measure changes that could have occurred through the year. Most importantly, this study provides support to theoretical claims made regarding the WWW and the impact it has on learning.

\section{Theoretical Framework}

The foundation of this study draws on interwoven contexts framing the environment in which learners participated. Students engaged in on-line information-seeking activities, partnered with technological tools designed to support inquiry, and received substantial scaffolding. As a result, students were expected to develop new science content understandings.

\section{Information Seeking and Content Understandings}

Numerous researchers described information seeking in electronic environments similar to the WWW. These descriptions suggest information seeking is a special case of problem solving (Marchionini, 1989) in which learners recognize and interpret an information problem, establish a plan of search, conduct the search, evaluate the results, and use information to solve a problem (Kuhlthau, 1993; Wallace, 1997). Whereas undirected searching leads to unexpected links or discrepant events related to their topic, highly directed searching is purposely used to find specific information (McNally \& Kuhlthau, 1994). As learners engage in information-seeking activities, they move through predictable stages (i.e., initiation, selection, exploration, formulation, collection, presentation) and progress from ambiguity to clarity and from seeking general information to seeking specific information (McNally \& Kuhlthau, 1994). Kuhlthau (1993) indicated that learners "construct their own points of view or understanding of a topic or problem" and increase their interest and confidence as they progress from initial conceptualizations of questions to the conclusion of the process.

In addition to information seeking, a variety of literature (Nickerson, 1995; Perkins, Crismond, Simmons, \& Unger, 1995; Perkins \& Simmons, 1988; Talsma, 1997) defined the nature of science content understandings. Content understanding is not only a recollection of facts and definitions associated with a particular subject area, but also the use of mapping schemes to associate concepts with referents and strategies for memorization and recall (Perkins \& Simmons, 1988). Similarly, content understanding can be viewed as a matter of degree in which an individual understands concepts, principles, structures, or processes at a relatively deep level and is able to demonstrate certain behaviors (Nickerson, 1995). Therefore, understandings could be made evident to others in terms of overt behaviors as learners communicate or act in three ways (Perkins et al., 1995):

1. Offering explanations. Learners display this kind of understanding by giving examples, highlighting critical features, and responding to new situations. Learners who simply present facts and describe phenomena without the ability to explain concepts clearly lack understanding.

2. Articulating richly relational knowledge. Learners express this kind of understanding with explanations that link to related aspects of a concept or phenomena. Learners who use sparse knowledge involving one simple rule would display poor understanding.

3. Displaying a revisable and extensible web of explanation. Learners demonstrate this kind of understanding by revising and extending explanations beyond the original source of information (i.e., textbook, lecture, video, experiment) to new contexts or situations. 
Learners who simply repeat back explanations and cannot extend them to new contexts lack robust understanding.

The notion of making depth of understanding public through explanation, articulation, and extension provides a concrete method of classifying learners' understandings. These newly constructed understandings are fragile and are subject to modification based on new information and additional learning experiences (Perkins et al., 1995).

Although the literature characterized the information-seeking process in electronic environments and provided definitions for science content understandings, the question of how the information-seeking process might interact with students' development of understanding is still unanswered. Using fine-grained data collection and analysis techniques, this study is designed to provide substantial insight into how learners construct understandings from using on-line resources.

\section{Characteristics of the $W W W$}

A large body of literature (e.g., Gordin, Gomez, Pea, Fishman, 1996; Lea \& Scardamalia, 1997; Linn, 1996) showed that some characteristics of the WWW, such as providing a hypermediabased environment and increasing access to primary resources via networks, are beneficial for learners.

Hypermedia can be defined as a method for organizing, structuring, and accessing information around a network of multimedia nodes connected together by links (Conclin, 1987). Browser software takes advantage of hypermedia design principles to make information easily accessible on the WWW. Users simply click on text (hypertext), graphical buttons (icons), or images (image maps) to navigate through various networks, sites, and pages within sites in a nonlinear manner. A hypermedia system permits the integration of text, graphics, audio, animation, and video into a "multidimensional learning environment" (Shepardson \& Britsch, 1996), allows users to move easily among vast quantities of information allowing freedom from the linear, highly directed flow of printed text (Marchionini, 1988), and provides opportunities for the "exploration of alternatives" that can result in the understanding of relationships that were previously unrecognized (Heller, 1990). Thus, Salomon, Perkins, and Globerson (1991) suggested that learners can develop "intellectual partnerships" with hypermedia-based programs as the programs assume part of the burden of information processing as information is located, retrieved, and presented in a common format on the computer screen.

In addition to the affordances that hypermedia holds for learners, access to primary resources via networks provides unique opportunities for the construction of new understandings. The nature of Web-based resources is different from the resources normally available in Grade $\mathrm{K}-12$ schools (Wallace, Krajcik, \& Soloway, 1996). These readily accessible resources usually contain current and comprehensive content from primary resources that are represented in various formats. They allow students to obtain up-to-date information in many content areas, use the same data and information sources as scientists do, manipulate and receive information in various ways, and acquire a variety of information through a single computer. Students can take advantage of primary resources in a variety of ways (Hoffman, 1997), including information gathering for research papers, reports, topic summaries, presentations, and other content-rich activities.

This study involved students using primary resources for their information-seeking activities. The availability or nonavailability of these resources may affect students' capacity to engage in on-line investigations and to develop content understandings. Thus, this study seeks to understand in what ways the quality of on-line resources might interact with the construction of their content understandings. 


\section{Use of WWW in Science Classrooms}

Potential uses for the WWW in science classrooms have been explored by educational researchers (Barrie \& Presti, 1996; Gordin, Gomez, Pea, \& Fishman, 1996; Ryder \& Graves, 1997; Tinker, 1996). As mentioned previously, however, empirical studies indicated that students face specific challenges, such as having difficulty locating and taking advantage of information and being unable to evaluate the resources they find (Lyons et al., 1997; Wallace, 1997; Wallace et al., 2000).

These studies were conducted over short periods of time (1-2 weeks) and used limited sources of data, whereas this study used an extended perspective (4 curriculum units during the school year) and a variety of data sources, and considered pedagogical influences to understand fully the dynamics of classroom teaching and learning with the WWW. In addition, the previous studies suggested that students need to develop searching and assessing strategies when engaging in on-line inquiry by using the WWW. In response to this suggestion, this study developed scaffolding on-line and off-line materials to support students' information-seeking activities. In the following section, we provide a detailed account about these materials and pedagogical supports in the learning environment where the study was conducted.

\section{Learning Environment}

The participants of this study engaged in four weeklong investigations with the goal of developing a solution or answer to a question they had posed. They were immersed in a learning environment designed to support question asking, resource gathering, and the construction of new understandings. This environment included a number of interrelated components: (a) the University of Michigan's Digital Library (UMDL); (b) Artemis, the interface to the Digital Library; (c) the Middle Years Digital Library (MYDL), on-line learning materials; and (d) Tactics and Strategies for Leading On-Line Investigations (Hoffman \& Eccleston, 1997), off-line curriculum materials. Although explained individually, they comprised a coherent whole for attempting to engage students in on-line inquiry and provided scaffolding to support on-line inquiry.

Drawing from research on the use of scaffolding to support the learning process (Palinscar \& Brown, 1984; Paris, Wixson, \& Palinscar, 1986; Rosenshine \& Meister, 1992; Wood, Burner, \& Ross, 1976), this study viewed scaffolding as a process of providing decreasing amounts of support to help students "bridge the gap between their current abilities and the intended goal of instruction" (Rosenshine \& Meister, 1992, p. 26) that allows students "to participate at everincreasing levels of competence" (Palinscar \& Brown, 1984, p. 122). Scaffolding appears in many forms ranging from print-based materials to modeling behaviors enacted by the teacher. These scaffolding materials or procedures often begin with simple exercises that allow learners to participate in difficult tasks or activities early on in their inquiry. Through a series of closely monitored steps, difficulty is gradually increased as students become more involved with their learning, and finally the support by the teacher is withdrawn. This scaffolded instruction allows students to gain appropriate experiences and skills to increase their cognitive capabilities toward the task.

\section{$U M D L$}

The UMDL Project created an architecture and software infrastructure for the development of a digital library open to multiple heterogeneous collections. This digital library consisted of sites and pages identified by librarians as primary resources for middle and high school students in earth and space science classes. Students used the digital library to access on-line resources related to their questions. By providing preselective, high-quality, organized, and age-appropriate 
collections, the UMDL had a potential to influence the degree to which students engage in information-seeking activities and to support the development of content understandings.

\section{Artemis: Interface to the Digital Library}

A major component of this study was students' interactions with Artemis (Figure 1), a Javabased interface to the UMDL. This interface, including a research engine, driving question folders, and Broad Topics search, was designed to support on-line information seeking (Wallace et al., 1998). Artemis provides a permanent workspace and allows students to focus on the task of inquiry rather than concerning themselves with organizing their workspace, recalling pass searches and sites, and recording addresses of useful sites.

Driving question folders provide support by encouraging students to reflect on useful sites they find (as well as their question) before placing the resources in folders. The folders provide a permanent workspace for students where they can easily restore and retrieve resources for investigations. Broad Topics provide support by helping students generate keywords, recall prior knowledge, and view structures of a particular content area before initiating queries to the Digital Library. Collections also support students by providing useful resources pertinent to their driving question. Together, these features of Artemis scaffold students on-line inquiry by allowing them to focus on the contents of the resource, evaluate its usefulness, and synthesize information rather than spending the majority of time simply locating appropriate sites on the WWW.

\section{MYDL: On-line Learning Materials}

The MYDL provided printed and on-line learning materials to support middle school student inquiry on the WWW. MYDL included several Web pages to scaffold students' on-line inquiry. For example, a What to Do page gave a brief introduction to the science unit and the inquiry process. A Share page allowed students to click individual icons to reach on-line forms for sharing driving questions, sites pertinent to their questions, and comments or questions to other students.

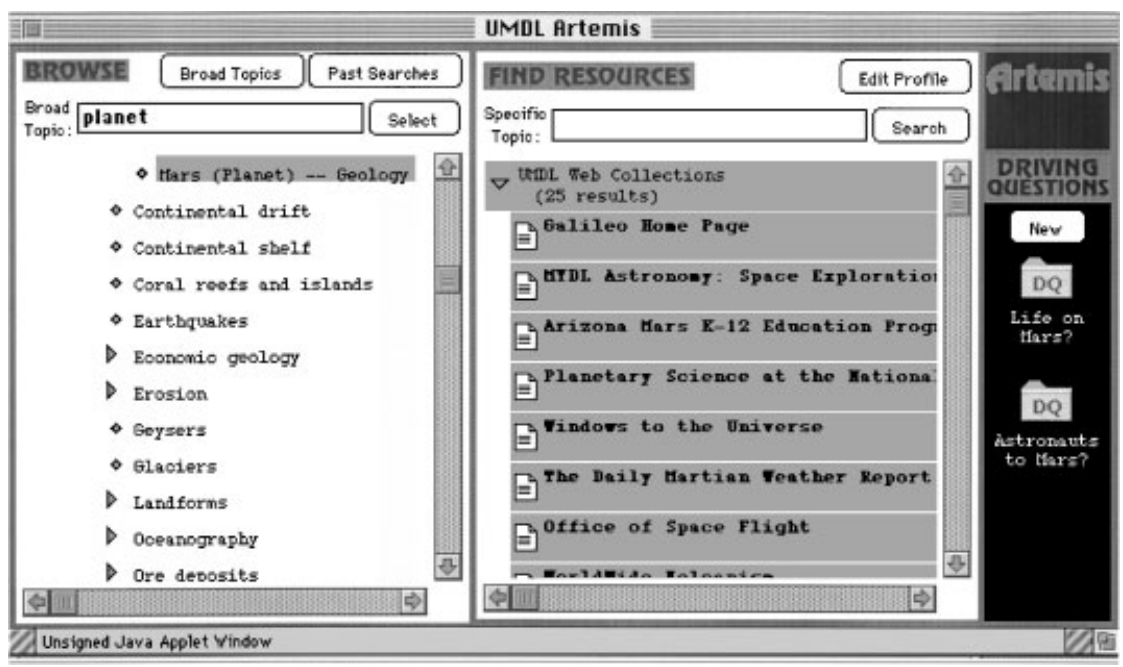

Figure 1. Artemis interface main screen. 
Students used these materials as a tool to support their information-seeking activities as they asked question of interest, planned their inquiry, searched for information, assessed their findings, and created rich representations of their newly constructed understandings. The design goal of MYDL on-line learning materials was to provide a common framework for learners as they participated in information-seeking activities across a number of content areas.

\section{Tactics and Strategies for Leading On-Line Investigations: Off-line Curriculum Materials}

This study recognized the importance of communicating a comprehensive pedagogical model to teachers and students in an effort to promote a high degree of participation and thoughtfulness with inquiry-based learning. Thus, this study developed a series of print-based scaffolding materials to support students and teachers during on-line units. Tactics and Strategies for Leading On-line Investigations (Hoffman \& Eccleston, 1997) was a series of booklets providing guidance for teachers who were new to the Web or unfamiliar supporting student-led inquiry. It contained activity sheets for students to use and provided a process model, such as the Investigation Wheel (Figure 2), for scaffolding strategies for inquiry (i.e., asking, planning, searching, assessing, writing, creating).

\section{Methods}

\section{Research Setting}

This study was conducted in a public middle school located in a medium-size Midwestern city, serving approximately 830 students and employing 40 full-time equivalent teachers. The school drew students from a majority of middle-class and upper-middle-class families with a wide range of educational backgrounds. This middle school contained two computerbased classrooms (labs) located in the media center, with one dedicated to MYDL. Although the classroom was small, it accommodated 15 student pairs on computers. All computers were Power Macintosh 5260/100 with 13-in. color monitors, wired to the Internet via an ISDN line. A single low-capacity laser printer was available to students. Downloads and uploads between student computers and Internet Web sites were normally accomplished in a few seconds or less, except for peak usage periods during the day when transfer times could be extended to $\geq 15$ seconds.

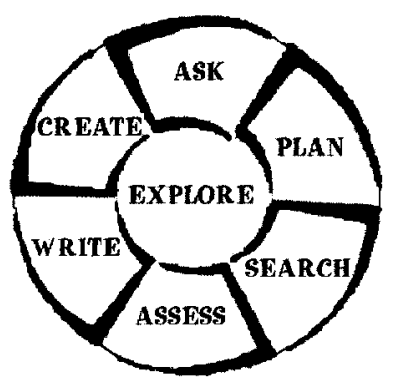

Figure 2. MYDL investigation wheel. 


\section{Participants}

Two teachers participated in this study. Nanci, ${ }^{2}$ the first teacher, had 10 years' experience teaching mathematics, science, geography, and foreign language at the middle school level. She had a bachelor of arts degree with teaching certification in mathematics and science and a master of arts degree in middle school curriculum. Nanci had participated in the MYDL project for 3 years and had used a number of on-line and print-based materials with her students. The second teacher who participated in this study, Heather, had 3 years' experience teaching language arts, science, and geography at the middle school level and 3 years teaching at a Montessori school. She had a bachelor of arts degree in psychology and English and was certified to teach general science and language arts. Heather had participated in the MYDL project for 2 years and had used a number of on-line and print-based materials with her students.

Eight pairs of sixth-grade science students (4 girls, 12 boys) were selected for this study: 4 pairs from Nanci's class and 4 pairs from Heather's class. These students were nominated as the target students by considering their genders, ethnic backgrounds, learning achievement in the past 2 years and abilities to verbalize their learning process. Among 16 target students, 3 were African Americans, 3 were Asian Americans, and others were European Americans.

\section{Participant Activities}

This yearlong study involved students using the MYDL Scavenger Hunt and four MYDL content units (astronomy, ecology, geology, or weather) during the school year. The Scavenger Hunt, a tutorial-like set of Web pages, was designed as a sequential 5-day introductory unit to help students become familiar with navigation, exploration, and Artemis, the interface to the Digital Library. In addition, students interacted with Artemis to create driving question folders, performed simple searches, and located specific information on a topic of their choice. Subsequent content units provided a series of on-line materials for students to use as they investigated questions related to specific topic areas. Teachers cooperating in this study used the inquiry-based pedagogy outlined in the Tactics and Strategies for Leading On-line Investigations manual as a basis for implementation with students.

\section{Data Sources}

The second author collected a variety of data sources during a 9-month period. She was technical resource person in the lab and interacted with the students for their content questions and tool problems during their on-line investigations. The data focused on the nature of their emerging content understandings. Process video captured activities on a computer screen and conversations of target student pairs (Krajcik, Simmons, \& Lunetta, 1988) and was collected for each student pair during all on-line sessions. These tapes were the primary source of data that allowed detailed insight into student conversations and use of on-line resources when engaging in informationseeking activities.

Student artifacts, including MYDL activity sheets, on-line postings, posters, journals (Wonder Books), and reports, were collected from students after each unit. Activity sheets contained students' written responses to inquiry-scaffolding questions, specific notes (title, URL, and main ideas) about resources encountered, comments about the trustworthiness of a site, and other question prompts related to students' inquiry. On-line postings included students' driving questions and subquestions, comments and questions to the teacher or peers, and critiques of sites used during the on-line unit. Students recorded their searching plans, results, and comments on 
their journals (Wonder Books). These artifacts (along with student interviews) provided a basis for the analysis of emerging content understandings of student pairs.

A number of semistructured interviews were conducted with student pairs outside the science classroom either during class or after school. These short (20-minute) interviews occurred approximately 1 week after the end of each on-line unit to assess the accuracy and depth of science content understandings. Interview questions probed understandings developed through inquiry with on-line resources (i.e., "Pretend I'm a reporter and want to find out about black holes. What can you tell me about them?"). Specific questions were posed to observe whether student understanding was limited to simple recall or could be explained, articulated, or extended (e.g., "What do you mean when you say a star is a middle star?"). These data along with student artifacts lent particular support to the content understanding research subquestions.

Classroom-lab video was recorded for prelab, in-lab, and postlab discussions and instruction given by the teacher. These videos occurred in the regular or computer classroom (lab) and captured both the teacher's voice and student responses. The classroom video provided a perspective on the type of background, support, and instruction the teacher provided to students and how they responded to these scaffolds.

\section{Data Analysis}

Two stages of analysis were performed on the data collected during the study: (a) analysis of individual data sources, and (b) data synthesis to assess student content understandings, Search and Assess strategies, and the quality of on-line resources.

\section{Analysis of Individual Data Sources}

STUDENT INTERVIEWS. Interview data were transcribed and used a perspective of content understanding as described by Perkins, Crismond, Simmons, and Unger (1995). Major categories for coding depths of understandings were Recalling Information, Offering Explanations, Articulating Relationships, and Extending Explanations. Further coding divided content understandings into distinct areas of knowledge [interpreted from Bloom (1974)]. Table 1 illustrates the coding scheme used to analyze the depths of content understandings.

To determine the accuracy of understanding, interview transcripts were coded into four divisions: Incorrect, None, Partial, and Accurate, under the four major categories. When a response was considered incorrect or not accepted as factual in scientific terms or represented an alternately held conception, it was coded as Incorrect. A response was coded as None when the accuracy of understanding was demonstrated by a lack of response or the inability to extend a description or explanation to a higher level of understanding (i.e., "I do not know"). When a response was for the most part correct but contained some element of incorrect information or a hesitancy to respond, it was coded as Partial. When an accurate response was provided without incorrect or erroneous information, it was coded as Accurate.

PROCESS VIDEO. Process videotapes were viewed, coded, and summarized. Episodes of student activity related to students' search strategies and assessment of resources were transcribed. Search strategies were coded when students developed possible search topics, queried the UMDL, and selected useful resources, such as navigating deep into sites, browsing the contents of pages, and pausing to read information related to their investigations. Assess strategies were coded when 
Table 1

Coding scheme for depth of content understanding

\begin{tabular}{|c|c|c|}
\hline Level & Code & Description \\
\hline \multirow{4}{*}{$\begin{array}{l}\text { Recalling information } \\
\text { (stating, repeating) }\end{array}$} & RF & Recall specific facts and isolated bits of information. \\
\hline & $\mathrm{RP}$ & $\begin{array}{l}\text { Recall processes, directions, and movements of phenomena } \\
\text { with respect to time. }\end{array}$ \\
\hline & $\mathrm{RM}$ & $\begin{array}{l}\text { Recall methods, techniques, procedures utilized to support } \\
\text { discovery and inquiry. }\end{array}$ \\
\hline & RT & Recall theories, patterns, principles, and generalizations. \\
\hline \multirow{4}{*}{$\begin{array}{l}\text { Offering explanations } \\
\quad \text { (telling, describing) }\end{array}$} & $\mathrm{EF}$ & Explain facts, information, and concepts. \\
\hline & EP & $\begin{array}{l}\text { Explain processes, directions, and movements of phenomena } \\
\text { with respect to time. }\end{array}$ \\
\hline & EM & $\begin{array}{l}\text { Explain methods, techniques, procedures used to support } \\
\text { discovery and inquiry. }\end{array}$ \\
\hline & ET & Explain theories, patterns, principles, and generalizations. \\
\hline \multirow{4}{*}{$\begin{array}{l}\text { Articulating relationships } \\
\quad \text { (expressing, relating) }\end{array}$} & $\mathrm{AF}$ & Articulate facts and concepts. \\
\hline & AP & $\begin{array}{l}\text { Articulate processes, directions, and movements of phenomena } \\
\text { with respect to time. }\end{array}$ \\
\hline & $\mathrm{AM}$ & $\begin{array}{l}\text { Articulate methods, techniques, procedures used to support } \\
\text { discovery and inquiry. }\end{array}$ \\
\hline & AT & Articulate theories, patterns, principles, and generalizations. \\
\hline \multirow{4}{*}{$\begin{array}{l}\text { Extending explanations } \\
\quad \text { (expand, revise) }\end{array}$} & $\mathrm{XF}$ & Extend facts and concepts. \\
\hline & $\mathrm{XP}$ & $\begin{array}{l}\text { Extend processes, directions, and movements of phenomena } \\
\text { with respect to time. }\end{array}$ \\
\hline & XM & $\begin{array}{l}\text { Extend methods, techniques, procedures used to support } \\
\text { discovery and inquiry. }\end{array}$ \\
\hline & XT & Extend theories, patterns, principles, and generalizations. \\
\hline
\end{tabular}

students assessed information obtained during the search process to determine whether it made sense, was interesting, and was trustworthy, and how it added to their understanding and inquiry. These episodes helped elaborate the analysis of how students who demonstrated deeper understandings search and assess on-line resources differently.

Process video was also used to evaluate the depth and accuracy of students' content understandings. Episodes related to understandings were transcribed and coded with a scheme similar to student interviews.

ARTIFACTS. Student artifacts constructed at the conclusion of each inquiry unit also provided a fine-grained perspective on the development of understandings. The physical appearance of these artifacts was described, printed text and presentation dialogue transcribed, and coded using the scheme developed for student interviews. In addition to final artifacts, in-process artifacts such as MYDL activity sheets, on-line postings, and journal writings provided additional support for gaining insight on the sense-making process.

CLASSROOM-LAB VIDEO. Classroom-lab video recordings were collected to describe the implementation of scaffolded on-line and off-line materials and provided a perspective on how pedagogical supports might promote students' engagement with information-seeking activities. These data were not coded and analyzed in detail; rather, they were used to display the major events of the day and particular episodes related to on-line inquiry. 


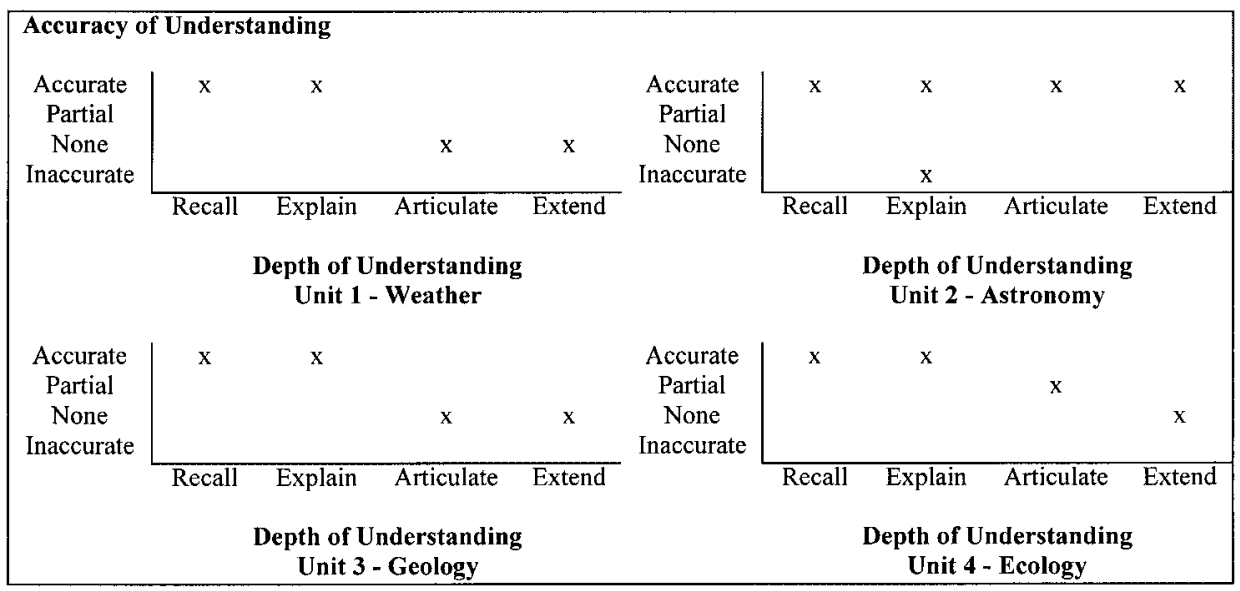

Figure 3. Content understanding summary for Angela and Jamie.

\section{Data Synthesis}

CONTENT UNDERSTANDINGS. To answer the research questions, we combined the data for process videos, artifacts and interviews. Divisions for depth of understanding (specific facts, processes, methods, and theories) were consolidated into a single data point for each category to provide a graphic summary (see Figure 3 for an example). Determination of these summary points was based on the presence of any division of understanding in the category and the highest accuracy of understanding. However, incorrect understandings were also included in the summary along with partial or accurate understandings. This represented a student possessing an accurate depth of understanding for a single concept in a topic, but at the same time holding possible incorrect conceptions. These analyses provided the bulk of empirical evidence to make claims regarding students' depth and accuracy of understanding.

SEARCH AND ASSESS STRATEGIES. In additional to content understandings, we identified inquiry strategies: Ask, Plan, Tools, Search, Assess, Write, Synthesize, and Create. In particular, we compared Search and Assess strategies for student pairs. This comparison allowed us to analyze how the use of strategies could possibly interact with students' development of content understandings and determined how students' strategies changed while engaging in multiple content units. A coding scheme (high, adequate, and low) was developed to rate students' engagement with each strategy (Table 2). Also, data from student artifacts helped inform the analysis and comparison of student pairs. Together, process video and artifact data were used to determine students' engagement in using Search and Assess strategies.

QUALITY OF ON-LINE RESOURCES. The design of Web sites students used during their on-line inquiry was evaluated. Process video and artifacts (including MYDL activity sheets, on-line postings, and final products) were reviewed to analyze the potential effect that Web page design had on the construction of student understandings. A coding scheme adapted from Hoffman, Kupperman, and Wallace (1997) was used to assess aspects (i.e., general design, context, navigation, content, interactivity) of Web site design for promoting the construction of 
Table 2

Engagement with search and assess strategies

\begin{tabular}{|c|c|}
\hline $\begin{array}{l}\text { Engagement } \\
\text { Level }\end{array}$ & Search Strategy \\
\hline High & $\begin{array}{l}\text { Students carefully develop a number of } \\
\text { possible broad and specific topics } \\
\text { relating to their driving question, } \\
\text { demonstrate thoughtfulness in the } \\
\text { use of these terms for queries to the } \\
\text { Digital Library, and are highly selective } \\
\text { in their choice of resources. Students } \\
\text { purposefully navigate deep into sites, } \\
\text { browse the contents, and pause to read } \\
\text { information related to their inquiry. }\end{array}$ \\
\hline
\end{tabular}

Adequate

Students develop a number of search topics related to their driving question and initiate queries to the Digital Library. Students are somewhat selective in their choice of resources but may not dig deep enough or commit adequate effort to locate information. Although students are eventually successful, some time is wasted in the search process.

Low

Students exert little thought and planning in their acquisition of resources, do not dig deeply to locate useful information, and often needlessly repeat searches. The success of their query is often based on luck rather than the careful use of search strategies. Students often waste a significant amount of time surfing rather than browsing for information.
Assess Strategy

Students have a thoughtful discussion about the potential usefulness of a site before pursuing its contents in-depth.

As students dig deep into the site, they judge whether the information is understandable, worthwhile, and trustworthy. Students also use multiple sources during their inquiry to compare and contrast the trustworthiness of information. When performing a formal critique of a site, students are able to provide a thoughtful assessment of both the appearance and content.

Students judge whether information is relevant to their driving question before investing time in a site. Decisions are based on the site's content rather than appearance or title. The majority of time is spent with worthwhile and understandable information; however, trustworthiness of the source is based solely on the URL (.org, .edu, .com, .gov). Students are able to provide a limited critique of a site's appearance and content.

Students are quick to decide on the relevancy of sites, and this determination is often based on the site's title or first page. Information is often accepted although it does not relate directly to the driving question. Students do not discuss the trustworthiness of the site and consider all information good information. They are unable to critique a site's appearance and content effectively.

understandings. This analysis focused on resources students spent time browsing, discussing, or writing about in MYDL activity sheets and journals. To investigate a possible connection between students' understandings and their use of on-line resources, comparisons were made between major sites students used during their inquiry and the depth and accuracy of understandings that could be possibly gained from those resources.

EMERGING THEMES. Themes emerged as a result of coding, analyzing, and evaluating data. As data were coded and analyzed, notes, reflections, and examples were recorded with particular attention paid to students' development of understandings, engagement with Search and Assess strategies, and their use of on-line resources. These recordings provided the basis on which to add to ideas and explore reoccurring themes. Themes were then verified by confirming and disconfirming evidence from the data corpus (Erickson, 1986). 


\section{Results}

\section{Content Understandings: Depth}

An analysis of process video, interviews, and artifacts shows that although students constructed meaningful understandings through on-line inquiry, the depth of their understandings varied. A majority of target students offered explanations, articulated relationships, and extended explanations during the interviews, but the explanations and relationships they provided were only partially accurate. Only few demonstrated the ability to expand accurate understandings to articulate and extend levels. In the following segment, Jamie could both articulate and extend their explanations.

\section{Angela and Jamie (Pair 3): Astronomy Investigation (Unit 2).}

Interviewer: Jamie, tell me what you learned about black holes.

Jamie: I learned that the black hole itself, the reason it is black and you can't see it is because it sucks in light and light cannot escape so you wouldn't see it and x-rays do detect them, but you don't see how big, you just see like the gravitational pulls and you can't see the particles ... and, like, when they find one they know, they can track down how much gravitational pull it has, but they don't know how wide it is and they really don't know what size.

Interviewer: Why does it pull things into it?

Jamie: I know. The reason it pulls it in is because when the star, like, when the supernova occurs it blows up and, like, the dust particles and stuff gets, like, pulled together because of space and then after that they just sort of suck everything in because they are use to having a gravitational pull in a certain direction, so it continues to do it and it sort of makes, like, a funnel kind of shape ... and everything sort of is just draining in it.

Interviewer: Anything else you learned about black holes?

Jamie: Well, ah, I wouldn't want to be sucked in one. It'd be, like, a painless way of committing suicide, though, because you'd only be alive for, like, a second.

Interviewer: Why would that be?

Jamie: Well, because it stretches you, it stretches you so much that you'd just be a strand of spaghetti and so because it's stretching you just collapse in on yourself.

Interviewer: Which would be a bad thing.

Jamie: Yeah [laughter].

This interview segment illustrates how some learners could reach beyond merely recalling information and express ideas with relating and linking concepts together, expanding concepts to new situations, and going beyond the original source of information.

On the other hand, some students were able to demonstrate accurate understandings in some units; however, the depths of these understandings were often limited to recalling information or offering simple explanations. The follow interview segment demonstrates how Edward and Kevin were confined to a simple restatement of facts (with sparse phrases) and could not provide additional explanation to specific questions. 
Edward and Kevin (Pair 2): Weather Investigation (Unit 1). Interviewer: What did you find out [about hurricanes]?

Edward: We found out that it needs seawater above $80^{\circ}$ or $90^{\circ}$ and that it is high pressure above the low pressure above the water and converging winds. That creates a hurricane and they go up like that.

Interviewer: So they go up...

Edward: It becomes like a cycle. They go up and it comes back down and it goes over and over again and it turns into a hurricane.

Interviewer: Kevin, anything to add to that? What did you learn about hurricanes?

Kevin: No, not much. Umm ... [long pause].

Although these students had some element of explanation in their responses, they had considerable difficulty moving beyond recalling discreet information. They were not able to explain that hurricanes require three conditions to form (and to strengthen): warm surface waters, high humidity, and the ability to concentrate heat vertically. This simple level of recall was typical of some learners participating in the study.

Students' understanding in terms of the four content units was also varied. Based on the analysis, a number of units had resulting understandings limited to recalling information (35\%) or offering explanations (32\%), and only a few demonstrated the ability to expand conceptualizations to articulate (22\%) and extend (12\%) levels. Some units (38\%) did not produce content understandings beyond partial accuracy.

An interesting observation made during the analysis of data was the stark difference between the depth of understanding apparent in student artifacts (including presentations) and those articulated during student interviews. A review of final products and presentations revealed little about the true depth of learners' content understandings; these artifacts often communicated a simple recall of factual information. Student interviews permitted a fine-grained view of these understandings, and concepts were probed to determine depths of conceptualizations. This was true for all levels of student pairs, including those with the weakest understandings. The following example illustrates the contrast between artifact and interview.

Karley and Brooke (Pair 8) created a simple poster for their weather investigation ("What is El Niño?"). One section reads: "What is El Niño? El Niño is a disruption of the ocean's atmosphere. In other terms it is when the ocean water changes it [sic] temperature, sometimes it changes by 1 degree, 2 degrees, and even up to 5 degrees. This change really affects the weather sometimes in good ways and other times in bad ways. El Nino can cause severe tornadoes, hurricanes, floods, etc. In good ways it can make your winters milder and nicer and springs seem earlier."

\section{Karley and Brooke (Pair 8): Weather Investigation (Unit 2).}

Interviewer: I noticed this winter we had a lot of warm days and we really didn't have as much rain or snow as we did normally. Why was that, if you said El Niño affected us? What caused us not to have as much cold or rain?

Karley: I think because, like, the cold weather we usually have was up more toward, like, Canada and the Upper Peninsula and we got what Tennessee and Kentucky usually have for their winters and that's usually just a little snow and warm days and stuff like that. 
Interviewer: Oh, I see. So what you're saying is it just kind of pushed all the weather up. Do you think we are going to have to worry about this next year?

Karley: Probably not. Probably the ocean temperature won't change like it did this year. It will just stay at normal temperature.

Brooke: Yeah, it will probably just stay. It will probably go back to its normal temperature. It won't change.

Although the artifact listed only general facts related to the change in weather patterns, students were able to offer additional explanations during the interview to illustrate a deeper understanding of weather phenomena.

\section{Content Understandings: Accuracy}

An analysis of process video, interviews, and artifacts indicates that most understandings students developed during the units were at the partial level (44\%), followed by the accurate level (39\%). A number of students developed (or held to) inaccurate understandings. This implies students more frequently developed limited understandings of concepts and had difficulty obtaining accurate conceptualizations.

The root of their alternate conception may originate from a connection made from topics learned previously in science class. When asked about the source of information on comet motion, Robert replied:

Umm, they (the Web) don't have a lot of information about it but we found out about the energy in science and it didn't exactly say that the energy makes the comet move, but we just, like, after planning together what it says and all the things we read that the energy does make it move, but it's also the thing that they're orbiting around.

Although Robert had some knowledge of gravitational influences, he admitted the "energy inside" has a "bigger effect" on motion. A review of students' final artifact (newspaper article) shows similar incorrect conceptions.

Exciting news from NASA today. Two comets that are traveling fast are on track to collide in 5 days at 9:30 p.m. If you are outside watching you will be able to see it. Scientists believe you will see bright sparks of blue. Then there will be a bright flash of red then nothing. The energy in the middle of the [sic] is supposed to mix gases together and make another comet but nobody in [sic] sure. Comets, like meteors and asteroids, are powered by the energy within them.

An interesting insight is the presence of a larger percentage of accurate understandings in Heather's students (24\% compared with 15\%) and a higher frequency of inaccurate understandings (13\% compared with $4 \%$ ) in Nanci's students. These inaccurate understandings may have resulted from an incorrect construction of understandings, or evidence of previously held conceptions.

\section{Strategies and Content Understandings}

One theme emerging from this study suggests a connection between students' engagement with inquiry strategies (including Ask, Plan, Tools, Search, Assess, Write, Synthesize, and Create) 
and the depth of their content understandings. In an analysis of 32 inquiries (8 pairs of students working on four content units), $70 \%$ of students who demonstrated adequate overall engagement with inquiry strategies possessed some evidence of accurate understandings with no incorrect conceptions. In contrast, $83 \%$ of students who demonstrated low engagement possessed only partial understandings or understandings containing some form of inaccurate conceptions. When comparing inquiries for engagement level and highest depth of understanding (at accurate or partial levels), $35 \%$ of students who demonstrated adequate engagement overall with inquiry strategies could articulate relationships or extend explanations. In contrast, $14 \%$ of students who had low engagement communicated understandings at these levels. These results imply that students' level of engagement with inquiry strategies may be related to the development of their content understandings.

Search Strategies. An analysis of process video and student artifacts may provide explanations for why students who highly or adequately engaged in on-line inquiry developed better content understandings. Students demonstrating accurate understandings and adequate and above engagement with Search strategies carefully developed a number of possible search topics relating to their driving question, demonstrated thoughtfulness in the use of these terms for queries to the UMDL, and were selective (high level) or somewhat selective (adequate level) in their choice of resources. Students purposefully (high level) navigated deep into sites, browsed the contents, and paused to read information related to their on-line inquiry. Evidence from process video (Tape 624B) and artifacts (MYDL Final Investigation Planning Sheet) depicts students' high engagement with Search strategies.

Edward and Kevin (Pair 2) pause to develop search topics for their ecology on-line inquiry unit ("Why Are Zebra Mussels Bad for the Great Lakes and My Community?") before loading Artemis. They record "Zebra Mussels, Mussel, Great Lakes, Boats, Swimming, Community, Lakes, Great" on their activity sheet for use with queries to the Digital Library. Edward and Kevin enter "Great Lakes" as a broad topic search and browse the list of topics returned, noticing that only "Lakes" is highlighted. They add "Zebra Mussels" as a specific topic, query the UMDL, and receive seven returns. Edward comments, "Look at all this information. Wow!"

Other evidence from artifacts (Student Journal entries) illustrates the thoughtfulness of students' topic selection and browsing during a geology unit.

We first went to our DQ folders to change their names. We then used geology for our broad topic. We looked in submarine geology and found volcanoes so we searched, we went into the UMDL collection of sites, and went into a volcanic hazard site. We then went to look at Fuego Volcano. The few graphics in the site were awesome, links, easy reading (about 8th-grade level). We explored about this volcanoes [sic] hazards, which were falling bombs, block, avalanches, and mud flows. We also explored its volcanic history. (Brad and Gabe, Pair 4)

Students demonstrating high engagement with Search strategies often invested more time than lower engaging pairs in the development of search topics. A review of process video activities for Brad and Gabe's (Pair 4) astronomy unit shows $2.3 \%$ of events devoted to commenting or discussing search topics. This contrasts with Grant and Robert (Pair 7), who had only $0.7 \%$ and demonstrated weaker content understandings. 
Students who demonstrated low engagement exerted little thought and planning in their acquisition of resources, did not click deeply into sites to locate useful information, and often needlessly repeated searches. An episode from process video (Tape 578A) illustrates students' poor use of strategies.

\begin{abstract}
Brooke and Karley (Pair 8) attempt to locate information on their driving question ("What are black holes?") during an astronomy unit. Students conduct a specific topic search on "black holes," receive 25 returns from the UMDL, and scroll through the list. Unfortunately, they do not see any returns with the words black hole in the title and assume the sites contain no information on their question. Brooke and Jamie continue to conduct a number of searches but invest little time in exploring the contents of returns or sites. Toward the end of the hour Karley comments, "This is, like, really pitiful. No one here knows what a black hole is. Everything on the Internet, nobody knows. Now to me that's pitiful.... No one on the Internet knows what a black hole is, they just know all this other scientific crap."
\end{abstract}

The success of their efforts was often based on luck rather than careful use of Search strategies, and as a result they wasted a substantial amount of time surfing rather than browsing for information. The poor use of Search strategies might defer the development of content understandings.

Assess Strategies. In addition to a high engagement in Search strategies demonstrated by students who demonstrated better content understandings, these students used more complicated strategies to assess on-line resources. They judged whether information was relevant to their driving question before investing time on a site. Decisions were based on a site's content rather than appearance or title. The majority of time was spent with worthwhile and understandable information; however, trustworthiness of the source was often based solely on the URL (e.g., .org, .com, .gov, .edu). They were able to provide a limited critique of a site's appearance and content. Evidence from process video (Tape 560A) and the MYDL Astronomy Cool Site Share Page illustrate students' engagement. The following episode demonstrates how students were thoughtful in their critique of resources and used content and appearance as measures of usefulness.

\begin{abstract}
Angela and Jamie (Pair 3) locate information on their astronomy question ("How do black holes form?") and pause to critique the site. Students discuss the ratings of various items on the MYDL Cool Site Share Page as they enter the information. "Black Holes and Neutron Stars, Description: This site had lots of interesting information. It was easy to find your way around and it had lots of interesting graphics. If you are studying black holes, this is a good site to look in. Critique: The appearance of Black Holes and Neutron stars is very interesting. The graphics were very interesting and informative. The content gave us most of our information that we needed to answer our driving question.” Angela and Jamie rated this site a 10 for overall appearance and 9 for overall content.
\end{abstract}

Most students who developed relatively weak content understandings through on-line inquiry did not adequately engage with Assess strategies. These students were quick to decide on the relevancy of sites, and this determination was often based on the site's title or first page. Information was often accepted although it did not relate directly to the driving question. Students did not discuss the trustworthiness of sites and considered all information good information. They were unable to critique a site's appearance and content effectively. An episode from process video (Tape 593A) illustrates this poor use of strategies. 
Brett and Cedric (Pair 1) locate a site for their geology unit ("Why do some volcanoes blow off half a mountain and some only trickle out lava?"). The site (Mount St. Helens: Volcano Page) has an attractive graphic, clear hypertext links, and little text. Cedric comments, "It's cool already." Brett immediately records information without looking through the site and brags to other groups, "Yeesh, oh my God, we found the best site ... God, look at this site, we found everything about Mount St. Helens!" Brett and Cedric scroll through one page at the site looking at small thumbnail images and short two-sentence descriptions. Brett pauses to record the title, URL, and a few comments about the site.

As illustrated, this pair focused more on the appearance of the site rather than its content. This episode was typical of students showing low engagement with Assess strategies.

\section{Quality of Resources and Content Understandings}

The analysis of process video suggests that to some degree, the quality of on-line resources was related to students' construction of content understandings. Sites that organized and presented resources in a logical manner allowed students to explore the full range of information available. Also, sites that presented engaging, easy to read information while combining it with other supports for learning fostered the construction of content understandings. However, the quality of sites did not seem to contribute directly to the construction of inaccurate understandings other than a poor presentation of information, lack of content, or low interactivity with resources.

Students who had broad and highly accurate understandings and demonstrated high levels of engagement with Search and Assess strategies could make use of poor-quality resources. These students used high-quality resources easily but through extended sense-making efforts could synthesize information from low-quality sites. However, students who demonstrated low engagement with strategies used both high- and low-quality sites equally as poor could not extract useful information and occasionally developed or held to inaccurate understandings.

\section{Discussion}

This study expanded on early attempts to describe how students interact and learn in on-line learning environments such as the WWW. Without data from pre- and postevaluations and a control group, this study was not designed to indicate a causal link between students' learning outcomes and their use of on-line resources. Yet, the analysis of students' understandings and their information-seeking activities suggests that students could benefit from access to on-line resources for inquiry-based activities if they are able to use Search and Assess strategies appropriately, resources are thoughtfully chosen, and support and scaffolding are extensively provided.

\section{Impact of Technological Tools on Information-Seeking Activities}

Students partnered with technology to enhance their general capabilities and learning as suggested by other research (Bereiter \& Scardamalia, 1987; Pea, 1985; Salomon, Globerson, \& Guterman, 1990; Salomon, Perkins, \& Globerson, 1991; Tinker, 1978; Tinker \& Papert, 1989). Although students experienced initial difficulty, they became increasingly proficient at using tools such as Artemis, and for a number of students these technological tools eventually became a seamless part of their inquiry activities. Although Owston (1997) claimed that the WWW 
and associated search engines are simply a vehicle to search and retrieve information, the learners in this study used tools in a manner that would suggest an "effect with technology" (Salomon, Perkins, \& Globerson, 1991). That is, technological tools support learners as a partner during intellectual tasks, where this support permits users to accomplish tasks faster and with less effort and to extend the range of their cognitive abilities and strategies. This study shows that as a research engine, Artemis supported students to engage in on-line investigation. Instead of spending an inordinate amount of time searching with engines such as Yahoo (Wallace et al., 2000), student pairs in this study were able to make efficient use of Artemis features and used Artemis to locate, organize, and view on-line resources related to their driving questions.

Additional evidence supports the notion that the quality of on-line resources facilitates learners information-seeking activities. Previous hypermedia research and literature described how easily accessible information could facilitate student inquiry (Marchionini, 1988) and could support learning by integrating images, sounds, and video to enable users to use vision, hearing, and language production as tools for building understandings (Shepardson \& Britsch, 1996). Other research (Heller, 1990; Jacobson et al., 1995; Jonassen, 1986; Marchionini, 1995; Nielson, 1990) reinforces the notion of providing organized and accessible resources to support open-ended information retrieval. In addition to the quality of resources facilitating student inquiry, new claims are made suggesting a relationship between on-line resource quality and the construction of learners' content understanding. As shown in the analysis of quality of resources, sites that presented engaging easy-to-read information while combining it with other supports for learning fostered the construction of content understandings. However, the use of high-quality sites did not guarantee improved understandings; it was more closely tied to learners' engagement with inquiry strategies.

\section{Applying Inquiry Strategies for Information Seeking}

This study suggests a connection between students' use of Search and Assess strategies during on-line investigation and their development of content understandings. The majority of students engaged at adequate and above levels with search strategies, whereas some students displayed poor strategies as described by earlier studies [e.g., Marchionini (1989)]. Highly engaged students were more deliberate in the selection of search topics, selective in the choice of sites, thorough in the browsing of information, and thoughtful in evaluating the content. Some students, however, were not able to use search strategies adequately. They used phrases instead of specific search terms, were not thoughtful about their selection of resources, and browsed for information haphazardly. This observation builds on earlier studies on information seeking in Web-based environments: Students require ongoing support to develop and refine their search strategies, which is often a critical component of their inquiry activities (Hill, 1999; Huston, 1991; Liebscher \& Marchionini, 1988).

In this study, although Assess and Search strategies were examined as separate categories of inquiry strategies, these two types of strategies were used seamlessly by highly engaged students. These students used Assess strategies to question the relevancy of a site before deciding on a board or specific topic for their next search. That is, how and what to search were determined by their evaluation of the sites, and the search results led to another assess-search cycle. Their decision was often based on the site's contents rather than the appearance. Student conversations and writings in this study provided a perspective in response to a need for developing student evaluation and critical thinking skills in information-seeking environments (Brouwer, 1997; Fitzgerald, 1997). 
It is not surprising that as novice learners of on-line inquiry the sixth graders in this study did not use multiple sources to verify the accuracy of information found on-line. Their discussions often centered on an assessment of the site's URL rather than biographical information provided by the author. On the other hand, a review of classroom-lab video did not contain episodes where teachers explicitly directed students to compare resources during the content units other than one activity where students compared sites with opposing viewpoints. This may reflect that students require specific intervention to develop various components of individual strategies. To help middle school learners reach higher levels of engagement with assess strategies, more scaffolding for search and assess strategies could have been provided. This echoes the argument presented by Metz (1995), that with sufficient learning scaffolding, young learners are capable of performing science inquiry, even though their investigations are less sophisticated than those of adults and adolescents.

\section{Pedagogical Practices and On-line Learning}

This study found some differences between student pairs from the two classes, and these variations might be attributed to the efforts of the participating teachers. Although teachers were provided with a model for inquiry-based learning, their implementation of supports and scaffolds were considerably different. Whereas one teacher provided substantial scaffolding to assist students in developing strategies for asking questions, planning inquiry activities, using on-line tools, searching for resources, assessing sites, writing about information, and creating artifacts, the other teacher provided less support. It seems that students benefited from an instructional environment where teachers provided clear expectations for classroom activities, provided critique, elicited feedback from students, and focused on scaffolding individuals and also the group as a whole. These findings are supported by Wisnudel-Spitulnik (1999) in an assessment of teacher scaffolding practices with learners engaged in dynamic modeling. She extended the knowledge base previously established by Collins, Brown, and Newman (1989) and Perkins (1996) by observing that learners benefited from teachers articulating expectations, modeling desired activities, and carefully orchestrating feedback.

\section{Mediating On-line Learning}

Although conducting on-line investigations could be beneficial for students, an important issue for continued use of the WWW for content learning surfaced during the analysis of data. Eighteen percent of inquiries involved inaccurate understandings as students conducted inquiry with on-line resources. Although an information-rich environment such as the WWW provides ample access to a variety of resources, it does little to mediate student learning, challenge students' existing understandings, and promote opportunities for accommodation. This points to more design work needed in another iteration of the tools, complementary curriculum and teacher practices.

Some students posed questions not supported by the UMDL collections. More extensive collections (e.g., other content areas, broader content areas, fact-based resources) might affect student engagement and subsequent construction of understanding. In addition, scaffolds that sequence students' searching process and provide prompts to help them evaluate the quality of online resources could be designed for Artemis.

Based on the findings with sixth graders, the Investigation Wheel (e.g., ask, plan, search, assess, write, create) could be refined such as adding a synthesizing phase into it. In addition, according to sixth graders' performance on on-line inquiry, curriculum materials that support advanced search and assess strategies could be developed for seventh or eighth graders. 
Teachers could provide more support to students as they attempt to make sense of information in an environment that does not foster the construction of understanding but merely provides information. Teachers should require students occasionally to suspend their on-line activities to have conversations about the information they are encountering. For example, teachers could encourage them to discuss questions such as what information is new to them, what information does not make sense, what they can do to know more, and what concepts they have learned would help them understand the new information. Through participation in these types of conversations, teachers can mediate student learning to enhance or correct in-process constructions of understanding.

\section{Conclusions}

This study expands on early attempts to describe how students interact and learn from on-line learning environments such as the WWW. Based on this work, it is clear that students can benefit from access to on-line resources when extensive support and scaffolding are provided by the teacher, but this is far from automatic. Expanded models for technology development, curriculum design, and pedagogical practices are required to instantiate on-line inquiry successfully through information seeking in content areas. Only through careful assessment of these models can the research community provide educators and policymakers with concrete guidance for using technological tools such as the WWW in today's schools.

This study was based on work supported by the NSF/DARPA/NASA Digital Library Initiative (Cooperative Agreement IRI-9411287) and by a grant from NSF NIE for the Middle Years Digital Library (RED-9554205). Any opinions, findings, and conclusions expressed in this study are those of the authors and do not necessarily reflect the views of the National Science Foundation.

\section{Notes}

${ }^{1}$ Artemis and its on-line learning activities are available at: http://www.webartemis.org.

${ }^{2}$ Pseudonyms for teachers and students are used throughout this report, maintaining their gender and ethnicity.

\section{References}

Barrie, J.M. \& Presti, D.E. (1996). The World Wide Web as an instructional tool. Science, 274, 371-372.

Bereiter, C. \& Scardamalia, M. (1987). The psychology of written composition. Hillsdale, NJ: Erlbaum.

Bloom, B.S. (1974). Taxonomy of educational objectives: The classification of educational goals. New York: D. McKay.

Brouwer, P. (1997). Hold on a minute here: What happened to critical thinking in the information age? Journal of Educational Technology Systems, 25, 189-197.

Brown, A.L. (1992). Design experiments: Theoretical and methodological challenges in creating complex interventions in classroom setting. Journal of the Learning Sciences, 2, 141-178.

Collins, A. (1999). The changing infrastructure of education research. In Lagemann, E.C. \& Shulmanm L.S. (Eds.), Issues in education research: Problems and possibilities (pp. 289-298). San Francisco, CA: Jossey-Bass. 
Collins, A., Brown, J.S., \& Newman, S. (1989). Cognitive apprenticeship: Teaching the crafts of reading, writing and mathematics. In Resnick, L.B. (Ed.), Knowing, learning, and instruction: Essays in honor of Robert Glaser. Hillsdale, NJ: Erlbaum.

Conclin, J. (1987). Hypertext: An introduction and survey. IEEE Computer, 20, 17-41.

Erickson, F. (1986). Qualitative methods in research on teaching. In Wittroc, M.C. (Ed.), Handbook of research on teaching (3rd ed.) (pp. 119-161). New York: Macmillan.

Fitzgerald, M.A. (1997). Misinformation on the Internet: Applying evaluation skills to online information. Emergency Librarian, 24, 9-14.

Gordin, D.N., Gomez, L.M., Pea, R.D., \& Fishman, B.J. (1996). Using the world wide web to build learning communities. Journal of Computer-Mediated Communication [On-line], 2(3). (Available: http://www.usc.edu/dept/annenberg/vol2/issue3/gordin.html).

Heller, R.S. (1990). The role of hypermedia in education: A look at the research issues. Journal of Research on Computing in Education, Summer 1990, 431-441.

Hill, J.R. (1999). A conceptual framework for understanding information seeking in open-ended information systems. Educational Technology Research and Development, 47, $5-27$.

Hoffman, J.L. (1997). A synthesis and analysis of current literature: The use of World Wide Web resources in secondary science classrooms. Unpublished manuscript, University of Michigan, Ann Arbor.

Hoffman, J.L. \& Eccleston, C. (1997). Tactics and strategies for leading on-line investigations. Unpublished manuscript, University of Michigan, Ann Arbor.

Hoffman, J.L., Kupperman, J., \& Wallace, R. (1997, March). On-line learning materials for the science classroom: Design methodology and implementation. In Soloway, E. (Symposium Chair), Using on-line digital resources to support sustained inquiry learning in K-12 science. Symposium conducted at the meeting of the American Educational Research Association, Chicago, IL.

Huston, M.M. (1991). Windows into the search process: An inquiry into dimensions of online information retrieval. Online Review, 15, 227-243.

Jacobson, M.J., Maouri, C., Mishra, P., \& Kolar, C. (1995). Learning with hypertext learning environments: Theory, design, and research. Journal of Educational Multimedia and Hypermedia, 4, 321-364.

Jonassen, D.H. (1986). Hypertext principles for text and courseware design. Educational Psychologist, 21, 269-292.

Kinzie, M.B., Larsen, V.A., Burch, J.B., \& Boker, S.M. (1996). Frog dissection via the World Wide Web: Implications for widespread delivery of instruction. Educational Technology Research and Development, 44, 59-69.

Krajcik, J.S., Simmons, P.E., \& Lunetta, V.N. (1988). A research strategy for the dynamic study of students' concepts and problem solving strategies using science software. Journal of Research in Science Teaching, 25, 147-155.

Kuhlthau, C.C. (1993). Seeking meaning: A process approach to library and information services. Norwood, NJ: Ablex.

Lea, N.S. \& Scardamalia, M. (1997, March). Progressive curriculum and knowledge building uses of networked multimedia resources. Paper presented at the meeting of the American Education Research Association, Chicago, IL.

Liebscher, P. \& Marchionini, G. (1988). Browse and analytical search strategies in a full-text CD-ROM encyclopedia. School Library Media Quarterly, 16, 223-233.

Linn, M.C. (1996). Key to the information superhighway. Communications of the Association of Computing Machinery, 39, 34-35. 
Lookatch, R.P. (1995). The strange but true story of multimedia and the Type I error. TECHNOS, 4, 10-13.

Lyons, D., Hoffman, J.L., Krajcik, J., \& Soloway, E. (1997, March). An investigation of the use of the World Wide Web for sustained on-line inquiry in a science classroom. Paper presented at the meeting of the National Association for Research in Science Teaching, Chicago, IL.

Maddux, C.D. (1996). The World Wide Web and the television generation. Computers in the School, 12, 23-30.

Marchionini, G. (1988). Hypermedia and learning: Freedom and chaos. Educational Technology, 28, 8-12.

Marchionini, G. (1989). Information-seeking strategies of novices using a full-text electronic encyclopedia. Journal of the American Society for Information Science, 40, 54-66.

Marchionini, G. (1995). Information seeking in electronic environments. Cambridge: Cambridge University Press.

McNally, M.J. \& Kuhlthau, C.C. (1994). Information search process in science education. Reference Librarian, 44, 53-60.

Metz, K.E. (1995). Reassessment of developmental constraints on children's science instruction. Review of Educational Research, 65, 93-127.

Nickerson, R.S. (1995). Can technology help teach for understanding? In Perkins, D.N., Schwartz, J.L., West, M.M., \& Wiske, M.S. (Eds.), Software goes to school: Teaching for understanding with new technologies (pp. 7-22). New York: Oxford University Press.

Nielsen, J. (1990). Multimedia and hypertext. Mountain View, CA: AP Professional.

Owston, R.D. (1997). The World Wide Web: A technology to enhance teaching and learning? Educational Researcher, 26, 27-33.

Palinscar, A.M. \& Brown, A.L. (1984). Reciprocal teaching of comprehension-fostering and comprehension-monitoring activities. Cognition and Instruction, 1, 117-175.

Paris, S.G., Wixson, K.K., \& Palinscar, A.M. (1986). Instructional approaches to reading comprehension. In Rothkof, E. Z. (Ed.), Review of research in education. Washington DC: American Educational Research Association.

Pea, R.D. (1985). Beyond amplification: Using the computer to reorganize mental functioning. Educational Psychologist, 20, 167-182.

Perkins, D.N. (1996, April). Teaching for understanding. Paper presented at the annual meeting of American Educational Research Association, New York.

Perkins, D.N., Crismond, D., Simmons, R., \& Unger, C. (1995). Inside understanding. In Perkins, D.N., Schwartz, J.L., West, M.M., \& Wiske, M.S. (Eds.), Software goes to school: Teaching for understanding with new technologies (pp. 70-87). New York: Oxford University Press.

Perkins, D.N. \& Simmons, R. (1988). Patterns of misunderstanding: An integrative model for science, math, and programming. Review of Educational Research, 58, 303-326.

Rosenshine, B. \& Meister, C. (1992). The use of scaffolds for teaching higher-level cognitive strategies. Educational Leadership, 49, 26-33.

Ryder, R.J. \& Graves, M.F. (1997). Using the internet to enhance student's reading, writing, and information-gathering skills. Journal of Adolescent \& Adult Literacy, 40, 244-254.

Salomon, G., Globerson, T., \& Guterman, E. (1990). The computer as a zone of proximal development: Internalizing reading-related metacognitions from a Reading Partner. Journal of Educational Psychology, 81, 620-627.

Salomon, G., Perkins, D.N., \& Globerson, T. (1991). Partners in cognition: Extending human intelligence with intelligent technologies. Educational Researcher, 20, 2-9. 
Shepardson, D.P. \& Britsch, S.J. (1996). When dinosaurs roamed: Hypermedia and the learning of mathematics and science. Journal of Computers in Mathematics and Science Teaching, $15,7-18$.

Soloway, E., Guzdial, M., \& Hay, K.E. (1994). Learner-centered design: The challenge for human computer interaction in the 21 st century. Interactions, 1, 36-48.

Stoll, C. (1998, August 12). Net pioneer calls computers mostly a waste. The Dallas Morning News [On-line]. (Available: http://spyglass1.sjmercury.com/breaking/docs/049448.htm?st.ne. fd.mnaw).

Talsma, V.L. (1997). How can we measure student understandings in science? Unpublished manuscript, University of Michigan, Ann Arbor.

Tinker, R.F. (1978). Microcomputers: Applications to physics teaching. Physics Teacher, 16, $436-445$.

Tinker, R.F. (1996). Information technologies in science and mathematics education [On-line]. (Available: http://www.concord.org/pubs/pdf/enc-v7.pdf). Concord, MA: Concord Consortium.

Tinker, R.F. (1997). The whole world in their hands [On-line]. (Available: http:// www.concord.org/pubs/pdf/future.pdf). Concord, MA: Concord Consortium.

Tinker, R.F. \& Haavind, S. (1997). Netcourses and netseminars: Current practice and new designs [On-line]. (Available: http://www.concord.org/pubs/pdf/netcours.pdf). Concord, MA: Concord Consortium.

Tinker, R.F. \& Papert, S. (1989). Tools for science education. AETS Yearbook, 5-27.

Wallace, R., Krajcik, J., \& Soloway, E. (1996). Digital libraries in the science classroom: An opportunity for inquiry [On-line]. (Available: http://www.dlib.org/dlib/september96/umdl/ 09wallace.html). D-Lib Magazine.

Wallace, R. (1997). On-line information seeking in a sixth grade classroom. Unpublished manuscript. University of Michigan, Ann Arbor.

Wallace, R., Kupperman, J., Krajcik, J., \& Soloway, E. (2000). Science on the Web: Students online in a sixth-grade classroom. Journal of the Learning Sciences, 9, 75-104.

Winebrener, J. (1997). Take the Internet with a grain (pound?) of salt. Michigan Association for Computer-Related Technology Users in Learning, 17, 19-21.

Wisnudel-Spitulnik, M. (1999, April). Teaching for understanding: One teacher's use of instructional strategies to support model building. Paper presented at the annual meeting of the National Association for Research in Science Teaching, Boston, MA.

Wood, D.J., Burner, J.S., \& Ross, G. (1976). The role of tutoring in problem solving. Journal of Child Psychology and Psychiatry, 17, 89-100. 